\title{
End-of-life care for persons with advanced chronic obstructive pulmonary disease: Report of a national interdisciplinary consensus meeting
}

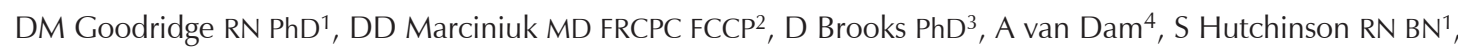
P Bailey RN PhD 5 , S Baxter MSW6, P Dorasamy MBChB FCPCMSA FCCP FRCPC 7 , S Dumont PhD ${ }^{8}, \mathrm{~S} \mathrm{Hassan} \mathrm{RRT}^{9}$, P Hernandez MD FRCPC ${ }^{10}$, A Kerigan MD ${ }^{7}$, G Rocker DM FRCP FRCPC ${ }^{10}$, D Wilson RN PhD ${ }^{11}$,

J Young RRT ${ }^{12}$

DM Goodridge, DD Marciniuk, D Brooks, et al. End-of-life care for persons with advanced chronic obstructive pulmonary disease: Report of a national interdisciplinary consensus meeting. Can Respir J 2009;16(5):e51-e53.

While systemic shortcomings in meeting the needs of individuals with progressive chronic illnesses at the end of life have been well documented, there is growing interest in improving both care and quality of life for persons with advanced chronic obstructive pulmonary disease (COPD). For instance, the American Thoracic Society has issued an official statement on palliative care for patients with respiratory diseases, affirming that the prevention, relief, reduction and soothing of symptoms "without affecting a cure" must become an integral component of standard care. A recent Medline search located 1015 articles related to palliative or end-oflife care for people with COPD published between 2001 and 2008, compared with only 336 articles published before 2001. To address the needs of Canadian patients, an interdisciplinary consensus meeting, funded by the Canadian Institutes of Health Research and supported by the Canadian Thoracic Society, the Canadian Respiratory Health Professionals and the Canadian Lung Association was convened in Toronto, Ontario, on November 22, 2008, to begin examining the quality of end-of-life care for individuals with COPD in Canada. The present report summarizes the background to and outcomes of this consensus meeting.

Key Words: Chronic obstructive pulmonary disease; COPD; Endof-life care

\section{Soins de fin de vie pour les personnes atteintes de maladie pulmonaire obstructive chronique avancée : Rapport d'une réunion consensuelle interdisciplinaire nationale}

Si on a bien documenté les lacunes de nature systémique qui nous empêchent de répondre adéquatement aux besoins des personnes atteintes de maladie chronique progressive en fin de vie, on note un intérêt croissant pour l'amélioration des soins et de la qualité de vie des patients qui souffrent de maladie pulmonaire obstructive chronique (MPOC) avancée. Par exemple, l'American Thoracic Society a émis un énoncé de position officiel sur les soins palliatifs à l'intention des personnes atteintes de maladie respiratoire selon lequel la prévention, le soulagement, l'atténuation et l'apaisement des symptômes ( sans objectif de guérison ») doivent faire désormais partie intégrante des soins standard. Une récente interrogation de la base de données MEDLINE a permis de recenser 1015 articles ayant trait aux soins palliatifs ou de fin de vie des personnes souffrant de MPOC publiés entre 2001 et 2008, comparativement à 336 articles seulement publiés avant 2001. Pour combler ce besoin au Canada, une réunion consensuelle pluridisciplinaire, rendue possible grâce aux Instituts de recherche en santé du Canada et appuyée par la Société canadienne de thoracologie, les Professionnels canadiens en santé respiratoire et l'Association pulmonaire, a eu lieu à Toronto, en Ontario, le 22 novembre 2008 pour amorcer une analyse de la qualité des soins palliatifs chez les personnes souffrant de MPOC au Canada. Le présent rapport résume l'historique et l'issue de cette réunion consensuelle.

In spite of the many unmet needs of patients with advanced COPD and their caregivers, disparities in access to specialized palliative care services at the end of life between patients with COPD and those with lung cancer have been widely reported $(4,19,20)$. Reasons for these disparities include 'prognostic paralysis', in which clinicians of patients with uncertain illness trajectories (such as COPD) procrastinate when considering the need for palliative care services; patient unwillingness to discuss endof-life care $(21,22)$; provider discomfort with initiating end-of-life dialogues (21); lack of financial resources (23); and lack of clinicians with expertise in the management of nonmalignant disease (23). Finally, the relative lack of evidence regarding the impact of incorporating palliative approaches into the care of people with advanced COPD (20) suggests that significant gaps in our knowledge base and, hence, patient management, remain. uals with chronic illness in the community $(5,8,10)$.

\footnotetext{
${ }^{1}$ College of Nursing; ${ }^{2}$ College of Medicine, University of Saskatchewan, Saskatoon, Saskatchewan; ${ }^{3}$ Department of Physical Therapy, University of Toronto, Toronto, Ontario; ${ }^{4}$ Canadian Lung Association, Ottawa, Ontario; ${ }^{5}$ School of Nursing, Laurentian University, Sudbury, Ontario; ${ }^{6}$ Canadian Hospice and Palliative Care Association, Ottawa, Ontario; ${ }^{7}$ Faculty of Medicine, McMaster University, Hamilton, Ontario; ${ }^{8}$ École de service social, Université Laval, Québec City, Québec; ${ }^{9}$ Medigas, Hamilton, Ontario; ${ }^{10}$ Faculty of Medicine, Dalhousie University, Halifax, Nova Scotia; ${ }^{11}$ Faculty of Nursing, University of Alberta, Edmonton, Alberta; ${ }^{2}$ Programme Extra-Mural Program, Atlantic Health Services Corporation, Saint John, New Brunswick

Correspondence: Dr Donna M Goodridge, College of Nursing, Room 423 Ellis Hall, Royal University Hospital, Saskatoon, Saskatchewan S7N OW8. Telephone 306-966-1478, fax 306-966-6703, e-mail donna.goodridge@usask.ca
} 


\section{Initiating the dialogue and end-of-life care planning}

- Clinicians should ensure that end-of-life care planning (which may include the completion of advance directives) occurs in a culturally safe manner for all patients with serious illness. End-of-life care planning should include dialogue about surrogate decision-makers, resuscitation, emergency treatment (including intubation) and ongoing mechanical ventilation, and be initiated as early as possible in the course of the illness before the end of life (American College of Physicians)

- End-of-life care planning may be initiated at diagnosis, if appropriate, to the patient's circumstances. Additional triggers for end-of-life care planning include situations in which there is serious impairment of functional status, the patient is asking questions salient to the end of life or when the provider would not be surprised if the patient died in the following 12 months

- The topic of end-of-life care planning should be first introduced by the health care provider most trusted by the patient, although physician involvement in the decision-making process is crucial. Families and significant others play a pivotal role in planning for the end of life of people with advanced COPD. The involvement of and ongoing dialogue with family members and significant others in end-of-life care planning needs to be strongly encouraged by providers

\section{Anticipating the need for end-of-life care}

- While accurate prediction of the trajectory of decline for a given individual with advanced COPD is challenging, the primary indicators that the patient is approaching the end of life are: a) poor functional status (Medical Research Council dyspnea scale 4 to 5 ); b) severe acute exacerbation; c) FEV less than $30 \%$ predicted; d) signs of respiratory failure or pulmonary hypertension; e) body mass index of less than $20 \mathrm{~kg} / \mathrm{m}^{2}$; or f) the patient is starting to wish for or talk about death. Deteriorating psychosocial/cognitive status and a pattern of increasing health care utilization are also useful indicators. Ongoing and focused monitoring (including the use of functional status scales such as the Palliative Performance Scale and the Bode Index) have prognostic value and should be used in both inpatient and home care settings

\section{Advocating for patient and caregiver preferences as to the site of end-of-life care}

- The specific location of both care and death is less important for persons with advanced COPD than implementing end-of-life care in a setting of their choice that accommodates both the patient's and caregiver's unique needs and preferences. The ability to access both inpatient and home support is a critical indicator of the quality of end-of-life care for people with advanced COPD. Alternative settings such as day hospices that may supplement care and relieve caregiver burden need to be explored

\section{Optimizing interdisciplinary team care}

- End-of-life care is optimized through continuity of direct care providers and access to an interdisciplinary team. Knowledgeable family physicians, nurse practitioners and case managers are the foundation of quality end-of-life care. Family physicians and home care teams should have access to the resources of both respiratory disease specialists and palliative care teams

- Enhanced collaboration among respiratory care providers and palliative care services will optimize quality of care. While palliative care specialists have an important role in consulting to provide symptom management, family physicians, respiratory specialists and home care providers must be trained to provide quality end-of-life care. Patients and families need clarification about the roles of each team member

- Specific initiatives designed to optimize end-of-life care for people with advanced COPD must be evaluated. These initiatives include $24 \mathrm{~h}$ emergency response teams for community-based patients (including same-day in-home response), dedicated case managers, system navigator models, rapid access to respite and palliative care beds in nursing homes and hospitals, and access to outpatient symptom management clinics. A strong evidence base, generated by high-quality research for best practices in end-of-life care for this population, must be supported by appropriate and sustainable funding

\section{Selecting interventions for patients with advanced COPD}

- Subjective symptom assessments (eg, Edmonton Symptom Assessment Scale) need to be routinely conducted in a consistent manner. Multidisciplinary interventions must address the whole person and include psychosocial, spiritual and existential dimensions. Screening for depression, fatigue, anxiety and caregiver burden, as well as appropriate interventions to alleviate these concerns, are critical. The use of opioids to manage dyspnea at the end of life may be a beneficial intervention. Interventions designed to enhance exercise tolerance, nutritional status or treat infection must be considered

- Interventions that may be detrimental to the quality of life of people with advanced COPD include sustained mechanical ventilation, 'emergency decisions' about life-sustaining therapies and cardiopulmonary resuscitation

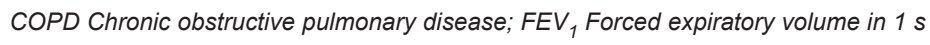

Calls for a new model of care for people with advanced $\mathrm{COPD}$, in which comprehensive palliative approaches are embedded within standard respiratory care, are becoming increasingly frequent $(2,24,25)$. The commitment to highquality care at the end of life is underpinned by a responsibility to evaluate and improve this care. Quality indicators (explicitly defined and measurable items referring to the structures, processes or outcomes of care [26]) are one means by which to evaluate end-of-life care quality that have been previously used with cancer populations (27-29). The primary focus at the Canadian consensus meeting was to discuss the applicability, development and monitoring of indicators measuring the quality of end-of-life care for individuals with advanced COPD.

The impetus for organizing this meeting was provided by the work two of the authors (DG, DM) had previously undertaken using administrative data to examine health care use of people with COPD who were in their last 12 months of life. Funding for the meeting was secured through a Canadian Institutes of Health Research Meetings, Planning and Dissemination Grant. Along with representatives from the Canadian Lung Association, the Canadian Thoracic Society, the Canadian Respiratory Health Professionals and the Canadian Hospice and Palliative Care Association (CHPCA), patients with COPD and their family members - an interdisciplinary, nationally representative group of professionals with an interest in end-of-life care for this population - were invited to participate in this initial one-day meeting.

\section{MEETING OUTCOMES}

Based on the findings of a preliminary Delphi survey conducted by DG (methodology and findings to be reported elsewhere) and designed to develop a draft of end-of-life care quality indicators for persons with COPD, a set of eight statements formed the basis for the group's discussion. The initial statements were revised using consensus methods. Five statements (Table 1) emerged to reflect group opinion regarding critical process and outcome indicators of quality end-of-life care for individuals with advanced COPD (Table 2).

\section{FUTURE PLANS}

Participants at the meeting agreed to move forward with an agenda to enhance end-of-life care for people with advanced 


\section{TABLE 2 \\ Consensus statements regarding outcome indicators of quality of end-of-life care for persons with advanced chronic obstructive pulmonary disease}

- Symptom control is the most critical indicator of quality of end-of-life care.
For this population, the symptoms of dyspnea, pain, depression, fatigue,
anxiety and fear must be considered
- Both system and patient-centred measures provide additional information
about how well we are caring for people dying from advanced chronic
obstructive pulmonary disease. These include measures of:
- Continuity of care;
- Informal caregiver burden;
- Patient and family satisfaction with care;
- Quality of life during the months or years the person is living with
advanced disease; and
- Timely, accurate communication between patients, caregivers and
providers. Further investigation must occur to determine how to best
measure each of these indicators and how to incorporate them into
practice

COPD. Strategies to accomplish this goal were identified and include validating the indicators emerging from this meeting with patients and families across the country, developing a national position statement on end-of-life care for this population, collaborating with the CHPCA to enhance training of respiratory professionals in end-of-life care using an established workshop format, promoting joint initiatives between respiratory professionals and the CHPCA, exploring the possibilities of purchasing items on representative national surveys that reflect lung health concerns and working toward monitoring selected key indicators on a national basis. To continue work on these initiatives, a Respiratory End-of-life Care Collaborative Group will be developed. Interested individuals may contact Donna Goodridge at donna.goodridge@usask.ca for further information regarding activities of the group.

FUNDING: Funding for this meeting was provided through a Canadian Institutes of Health Research Meetings, Planning and Dissemination Grant.

ACKNOWLEDGEMENT: Donna Goodridge is a Canadian Institute of Health Research/RPP New Investigator. Darcy Marciniuk is a Lung Association of Saskatchewan COPD Professor. Dina Brooks is a Research Chair in Rehabilitation in COPD. Shelly Hutchinson holds a Canadian Respiratory Health Professionals Graduate Student Fellowship.

\section{REFERENCES}

1. Murray SA, Boyd K, Sheikh A. Palliative care in chronic illness. BMJ 2005; 330:610-1.

2. Lanken PN, Terry PB, DeLisser HM, et al. An official American Thoracic Society Clinical Policy Statement: Palliative care for patients with respiratory diseases and critical illnesses. Am J Respir Crit Care Med 2008;177:912-27.

3. Claesens MT, Lynn J, Zhong Z, et al. Dying with lung cancer or chronic obstructive pulmonary disease; insights from SUPPORT (Study to Understand Prognoses and Preferences for Outcomes and Risks of Treatment). J Am Geriatr Soc 2000;48(Suppl 5):S146-153.

4. Gore JM, Brophy CJ, Greenstone MA. How well do we care for patients with end stage chronic obstructive pulmonary disease (COPD)? A comparison of palliative care and quality of life in COPD and lung cancer. Thorax 2000;55:1000-6.

5. Elkington $\mathrm{H}$, White $\mathrm{P}$, Addington-Hall J, et al. The healthcare needs of chronic obstructive pulmonary disease patients in the last year of life. Palliat Med 2005;19:485-91.
6. Solano FP, Gomes B, Higginson IJ. A comparison of symptom prevalence in far advanced cancer, AIDS, heart disease, chronic obstructive pulmonary disease and renal disease. J Pain Sympt Manag 2006;31:58-69.

7. ZuWallack RL, Haggerty MC, Jones P. Clinically meaningful outcomes in patients with chronic obstructive pulmonary disease. Am J Med 2004;117:49S-59S.

8. Edmonds P, Karlsen S, Kahn S, et al. A comparison of the palliative care needs of patients dying from chronic respiratory diseases and lung cancer. Pall Med 2001;15:287-95.

9. Barnett M. Chronic obstructive pulmonary disease: A phenomenological study of patients' experiences. J Clin Nurs 2005; $14: 805-12$.

10. Skilbeck J, Mott L, Page H, et al. Palliative care in chronic obstructive airways disease: A needs assessment. Palliat Med 1998; 12:245-54.

11. Tranmer JE, Heyland D, Dudgeon D, et al. Measuring the symptom experience of seriously ill cancer and non-cancer patients near the end-of-life with the Memorial Symptom Assessment Scale. J Pain Sympt Manag 2003;25:420-9.

12. Elofsson LC, Ohlen J. Meanings of being old and living with chronic obstructive pulmonary disease. Palliat Med 2004;18:611-8.

13. Seamark DA, Blake SD, Seamark CJ, et al. Living with severe chronic obstructive pulmonary disease (COPD): Perceptions of patients and their caregivers: An interpretative phenomenological analysis. Palliat Med 2004;18:619-25.

14. Guthrie SJ, Hill KM, Muers MF. Living with severe COPD: A qualitative exploration of the experience of patients in Leeds. Resp Med 2001;95:196-204.

15. Lacasse Y, Rousseau L, Maltais F. Prevalence of depressive symptoms and depression within patients with severe oxygen-dependent COPD. J Cardiopulm Rehab 2001;21:80-6.

16. Bergs D. 'The hidden client' - women caring for husbands with COPD: Their experience of quality of life. J Clin Nurs 2002;11:613-21.

17. Pinto RA, Holanda MA, Medeiros MCM, et al. Assessment of the burden of caregiving for patients with chronic obstructive pulmonary disease. Resp Med 2007;101:2402-8.

18. Fitzsimons D, Mullan D, Wilson JS, et al. The challenge of patients' unmet palliative care needs in the final stages of chronic illness. Pall Med 2007;21:313-22.

19. Goodridge D, Lawson J, Duggleby W, et al. Health care utilization of patients with chronic obstructive pulmonary disease and lung cancer in the last twelve months of life. Resp Med 2008;6:885-91.

20. Yohannes AM. Palliative care provision for patients with chronic obstructive pulmonary disease. Health Qual Life Outcomes 2007;5:17.

21. Curtis JR, Engelberg RA, Nielsen EL, et al. Patient-physician communication about end-of-life care for patients with COPD. Eur Resp J 2004;24;200-5.

22. Rocker GM, Dodek PM, Heyland DK, et al. Toward optimal end-oflife care for patients with advanced chronic obstructive pulmonary disease: Insights from a multicentre study. Can Respir J 2008; 15:249-54.

23. Murrary SA, Sheikh A. Palliative care beyond cancer: Care for all at the end-of-life. BMJ 2008;336:958-9.

24. Simpson AC, Rocker GM. Advanced chronic obstructive pulmonary disease: Rethinking models of care. Q J Med 2008;101:697-704.

25. Goodridge D. People with chronic obstructive pulmonary disease at the end-of-life: A review of the literature. Int J Pall Nurs 2006;12:390-6.

26. Mularski RA, Dy SM, Shugarman LR, et al. A systematic review of measures of end-of-life care and its outcomes. Health Res Ed Trust 2007;42:1848-70.

27. Earle CC, Park ER, Lai B, et al. Identifying potential indicators of the quality of end-of-life cancer care from administrative data. J Clin Oncol 2003;21:1133-8.

28. Grunfeld E, Lethbridge L, Dewar R, et al. Towards using administrative databases to measure population-based indicators of quality end-of-life care: Testing the methodology. Pall Med 2006;20:769-77.

29. Barbera L, Paszat L, Chartier C. Indicators of poor quality end-oflife cancer care in Ontario. J Pall Care 2006;22:12-7. 


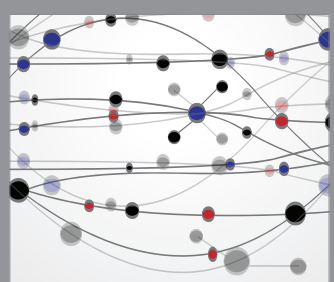

The Scientific World Journal
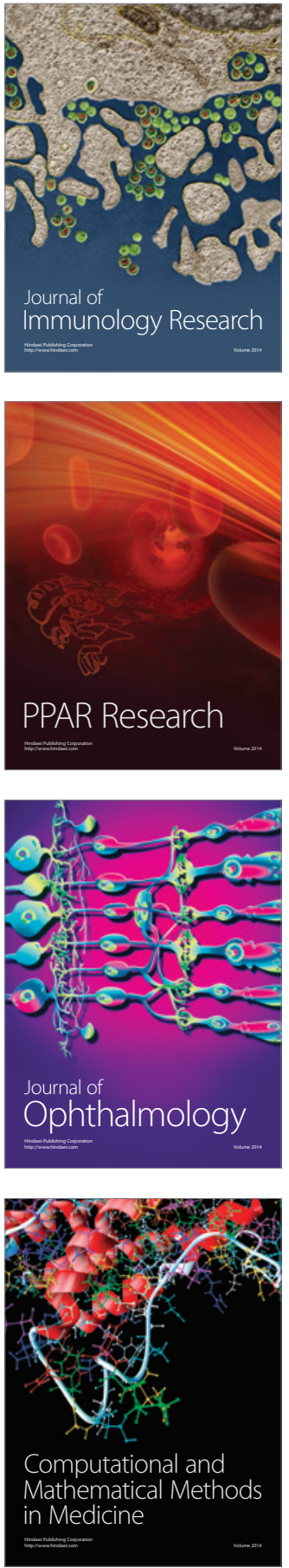

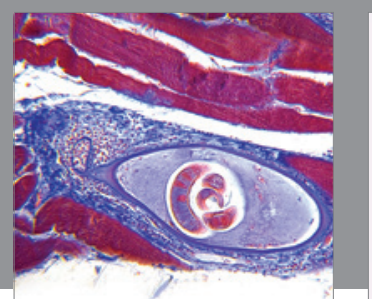

Gastroenterology Research and Practice

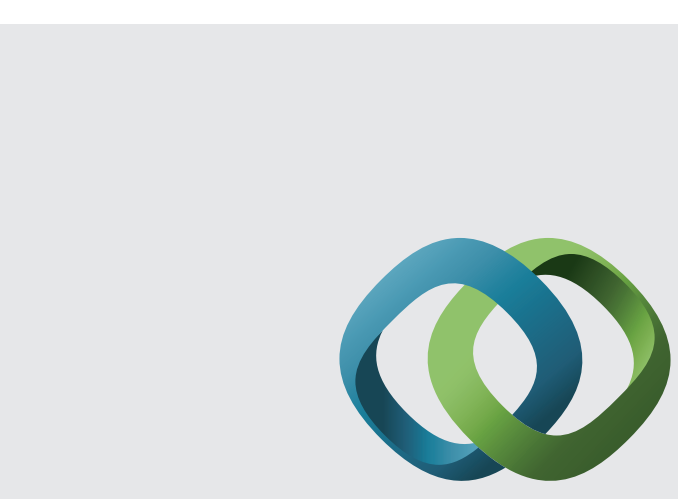

\section{Hindawi}

Submit your manuscripts at

http://www.hindawi.com
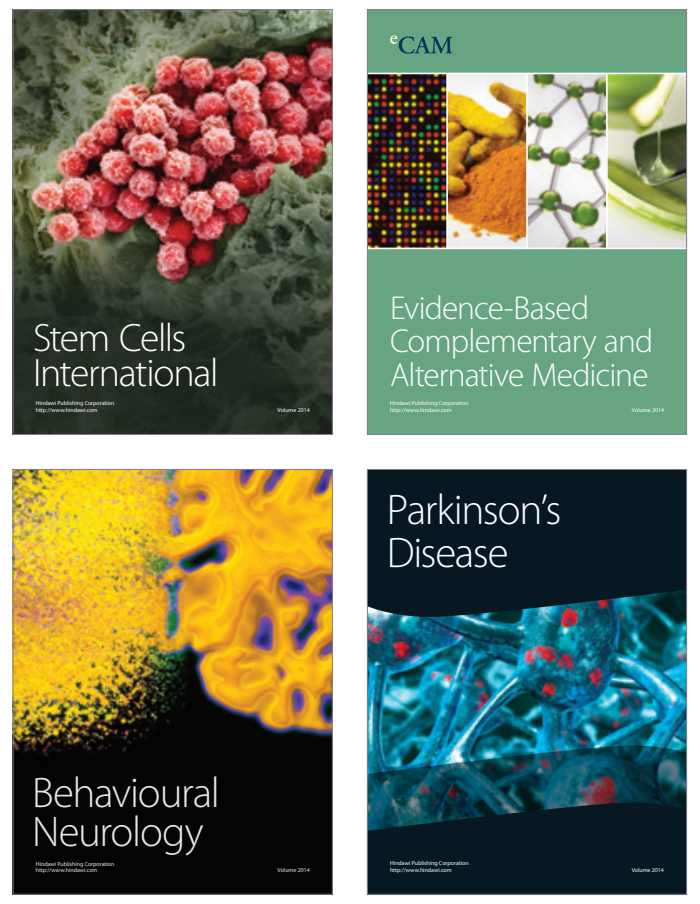
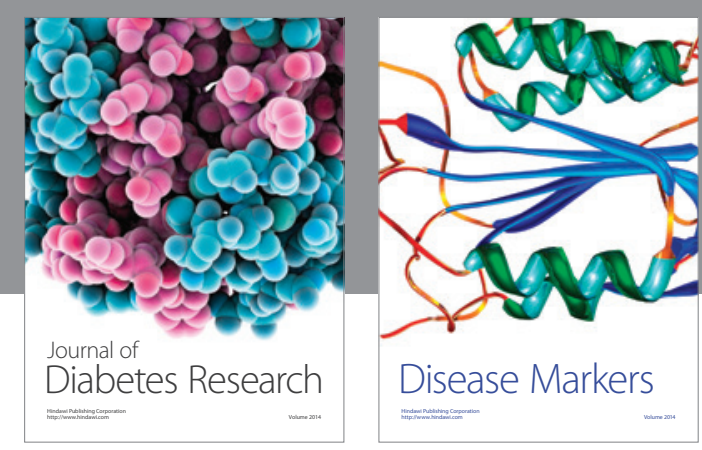

Disease Markers
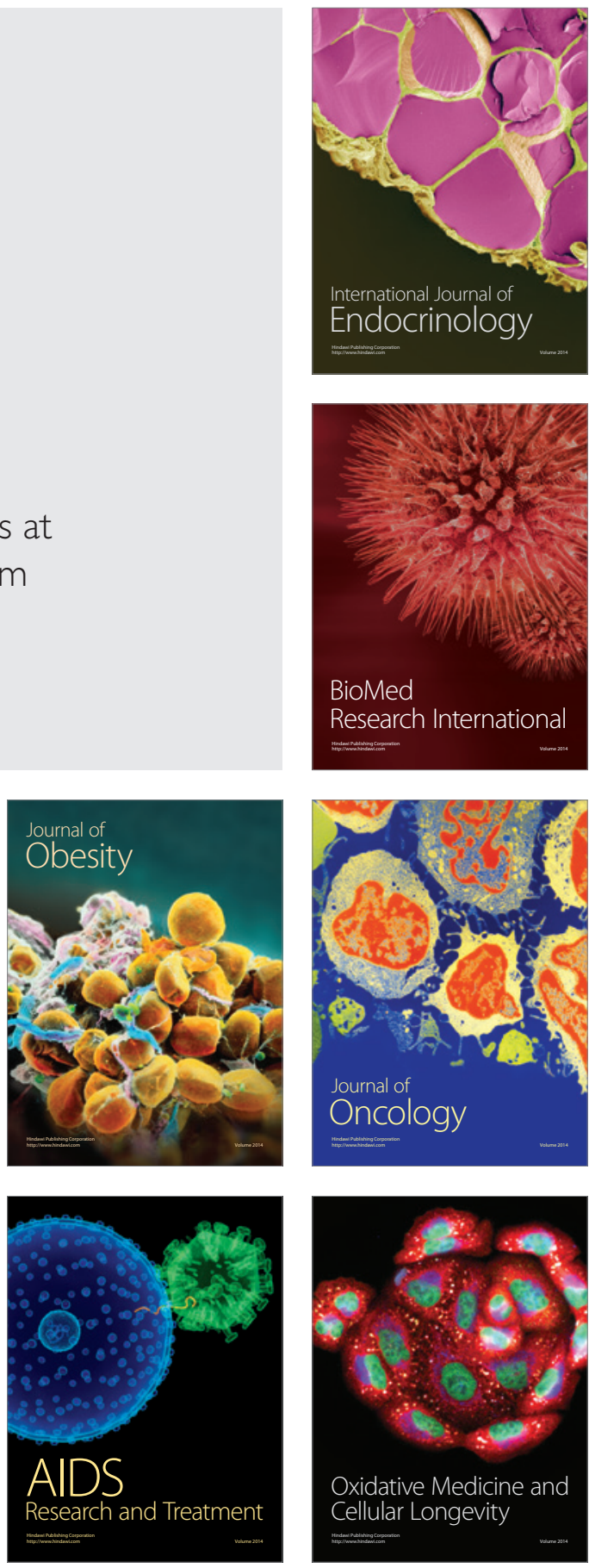